\title{
No food, no drinks
}

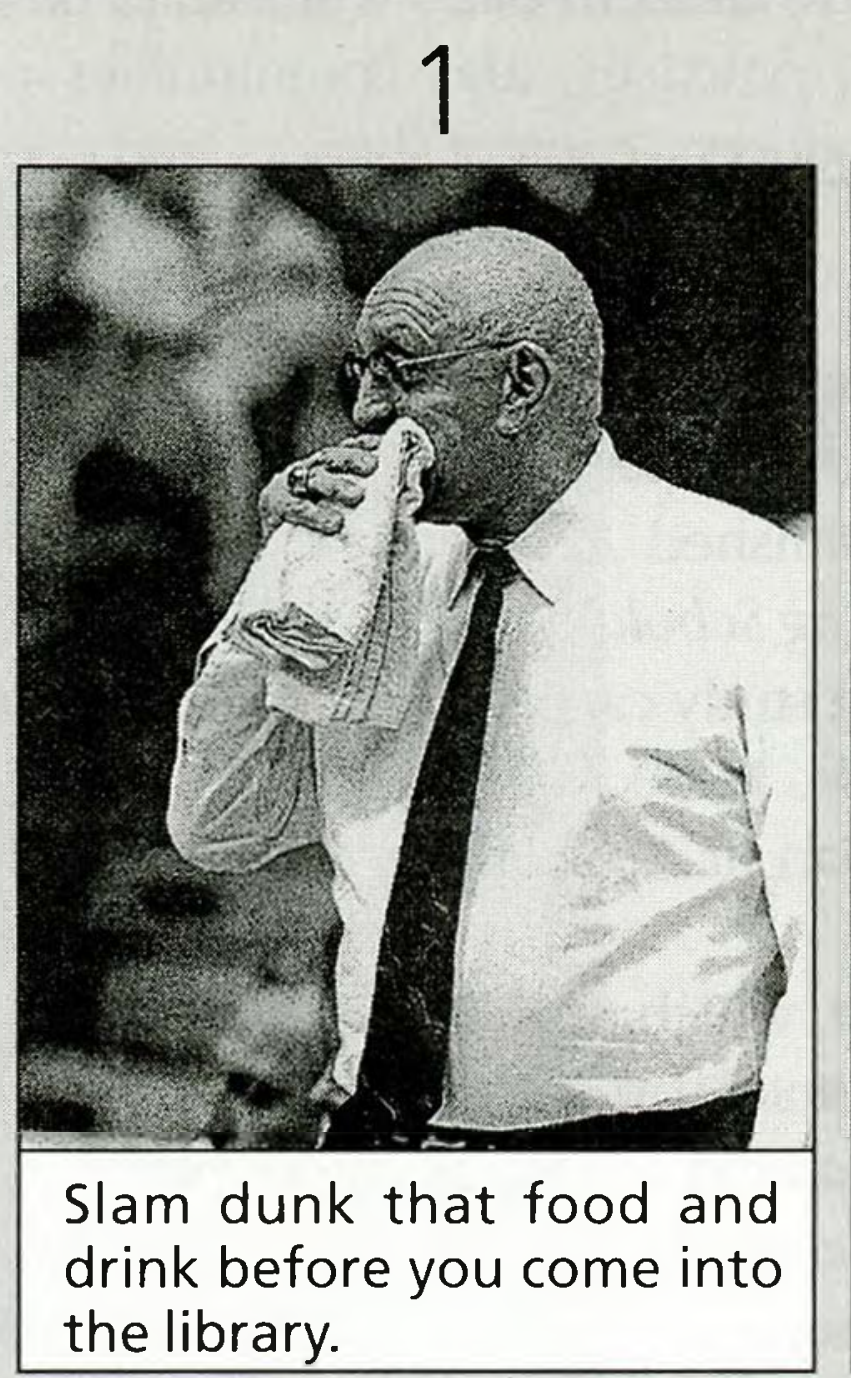

Food + drinks in libraries $=$ pests + dam age. Librarians everywher e are concer ned with this problem: patrons who bring in food and drinks that attract pests that destroy library materials. One solution to the problem is a "No food, No drinks" campaign.

The Henry Madden Library at Califor nia State University, Fr esno, has fought the good fight for several years with a continuing campaign using various poster designs and messages, ranging from an Uncle Samfinger pointing caricatur e of Library Dean Michael Gor man declaring "I want YOU to stop eating and drinking in the library" to W innie the Pooh with a honey pot stuck on his head.

The success of such a poster campaign is hard, if not impossible, to gauge, but the most $r$ ecent one appar ently made some impr ession on the patr ons of the Madden Library, if theft of the posters is any indication.

The popular posters depicted two wellknown campus coaches and the (Bulldog) mascot. Besides appealing to the $r$ ecognition factor of the subjects, the posters projected a sense of campus community spiritthat everyone uses, and should ther efore help car e for the library.

The athletic "celebrity" posters, with a variety of captions, lend a lighter, more

\section{2}
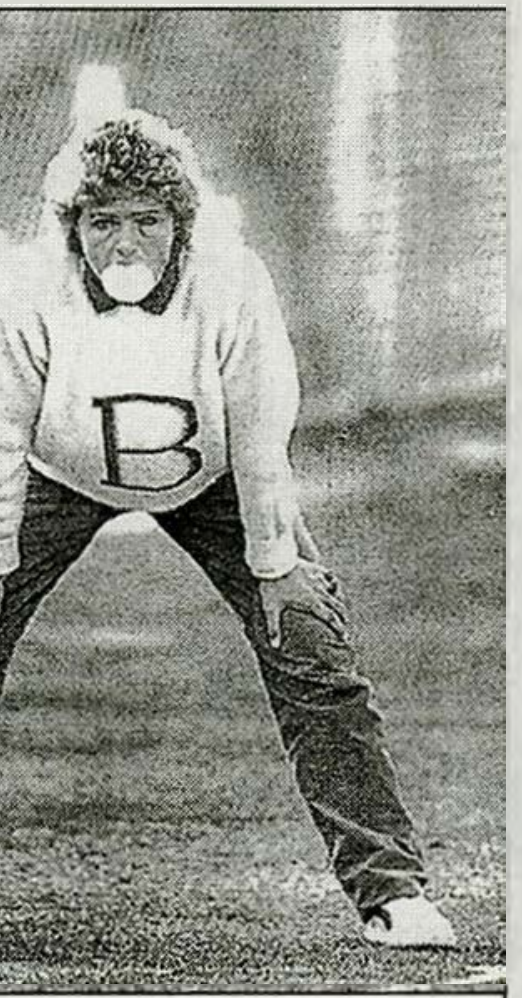

We hate to burst your bubble ... but food and drinks are not allowed in here.
3

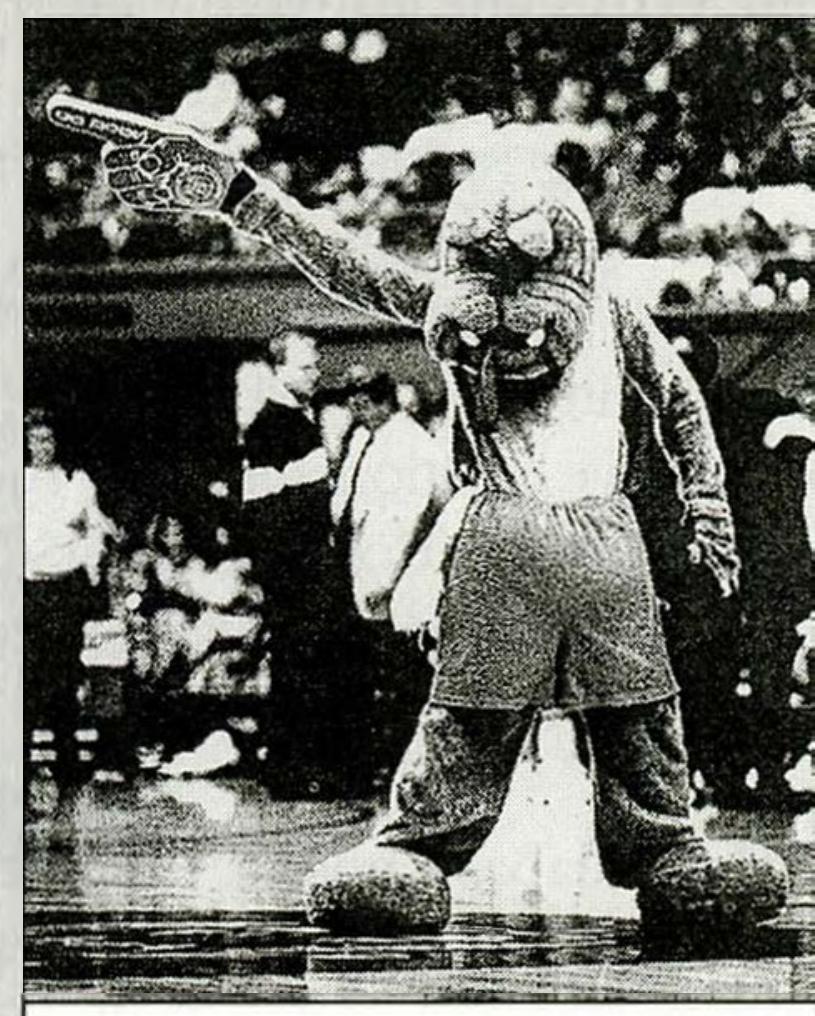

Doggone it! Keep that food and drink out of the library.

friendly, chiding tone to the ster n "No food, No drinks" admonition.

Photographs were obtained thr ough the campus Sports Infor mation Of fice; permission to use the images (with photo $\mathrm{Cr}$ edits) was granted by that of fice and the coaches after mock-ups of the posters wer e submitted.

Twelve posters were placed thr oughout the four-story library; five posters wer e stolen. No other posters in the library's campaign have proven to be as attentiongetting. We can only hope that the $r$ eal message - that food and drinks should not be consumed in a library-was appr eciated, as well.

\section{Notes}

1. Basketball coach Jerry Tarkanian with his trademark towel-biting gesture. Captions included "The library's out of bounds to eating and drinking" and "Foul! No eating or drinking allowed."

2. Olympic Gold Medalist and softball coach Margie Wright blowing bubble gum on the sidelines.

3. Time out, the Bulldog mascot, pointing a big foam finger.

- Janet Bancroft, Madden Library at California State University, Fresno; janet_brancroft@csufresno.edu 